\title{
Guidezilla extension catheter for percutaneous interventional therapy of complex lesions via a transradial approach: Case series from a single-center experience
}

\author{
Chen-yang Chen, Yi-yuan Huang, Liang Tang, Xin-qun Hu, \\ Zhen-fei Fang, Sheng-hua Zhou
}

Department of Cardiology, Second Xiangya Hospital, Central South University, Changsha, China

\begin{abstract}
Background: Guide catheter extension systems have become one of the most powerful tools for addressing complex lesions during percutaneous coronary intervention (PCI), but data on a new-generation rapid exchange extension catheter - the Guidezilla catheter - are limited. Summarized herein reports on experience using the Guidezilla catheter for complex coronary lesions via a transradial approach at the documented institution an evaluation of its safety and efficacy.

Methods: A total of 25 patients (19 males and 6 females) who underwent PCI via the radial approach with the Guidezilla catheter for adequate back-up support and to facilitate equipment delivery were enrolled. The clinical, angiographic and procedural data of all 26 procedures in 25 patients (1 patient underwent two PCI procedures on different lesions) were collected to evaluate the safety and efficacy of this novel equipment.

Results: The mean age of the enrolled patients was $67.7 \pm 8.41$ years old. The mean depth of intubation was $27.90 \pm 12.23 \mathrm{~mm}$. Stent implantation was successful in 23 out of 26 procedures (88.5\%) and failed in 3 cases: 1 case of tortuosity and severe angulation in a chronic total occlusion lesion; 1 case of an existing type B dissection (NHLBI classification system for coronary artery dissection types); and 1 case in which a stent was stripped off its balloon. None of the patients experienced coronary dissection, perforation, air embolism, pressure dampening or other major complications during the procedure.

Conclusions: The Guidezilla extension catheter is an effective and safe tool that provides improved back-up support and increases the success rate of PCI for complex coronary lesion by radial access. (Cardiol J 2018; 25, 2: 171-178)
\end{abstract}

Key words: extension catheter, Guidezilla, percutaneous coronary intervention, transradial, safety and efficacy

\section{Introduction}

With the dramatic development of surgical technique and equipment in recent years, the transradial approach has been increasingly used as the first choice for percutaneous coronary intervention (PCI) around the world due to good compliance in patients, reduced trauma and a low risk of hemorrhagic complications $[1,2]$. However, in complex cases, such as those with calcification, extreme tortuosity, severe angulation or chronic total occlusion, or if the delivery of a balloon or stent to the target lesion via the transradial approach is difficult due to poor back-up support and non-

Address for correspondence: Zhen-fei Fang, MD, PhD; Sheng-hua Zhou, MD, PhD, Department of Cardiology, Second Xiangya Hospital, Central South University, 139 Middle Renmin Road, Changsha, Hunan 410011, PR China, tel: 86-731-85292012, fax: 86-731-85294038, e-mail: zhenfeifang@sina.com (Zhen-fei Fang, MD, PhD); zhoushenghua_guo@163.com (Sheng-hua Zhou, MD, PhD) 
coaxiality. Therefore, methods to further improve back-up support using the original guide catheter and wire via the radial approach have been a hot topic. Several methods have been used to facilitate equipment delivery [1, 3, 4]; among them, guide catheter extension systems have been one of the most powerful approaches to providing adequate back-up support with minimal trauma to the proximal coronary artery [5].

The Guidezilla ${ }^{\mathrm{TM}}$ Guide Extension Catheter (Boston Scientific, Natick, USA) is a new-generation rapid exchange extension catheter system that has been called a child and mother catheter; it received Food and Drug Administration clearance in July 2013. This device was designed to facilitate the placement of interventional equipment and provide additional back-up support for the guide. Recent studies have revealed the safety and efficacy of using an extension catheter to address complex lesions [6-8]; however, most research studies have focused on the GuideLiner ${ }^{\mathrm{TM}}$ catheter (Vascular Solutions, Minneapolis, MN, USA), and thus, limited information on the Guidezilla ${ }^{\mathrm{TM}}$ Guide has been systematically collected, especially on its utility via the transradial approach.

Thus, the purpose of this study was to evaluate the safety and efficacy of the Guidezilla ${ }^{\mathrm{TM}}$ Guide Extension Catheter in addressing complex coronary lesions via the transradial approach based on the initial experience at this documented center.

\section{Methods}

A consecutive series of patients were retrospectively enrolled who had undergone complex PCI with the use of a Guidezilla ${ }^{\mathrm{TM}}$ Guide Extension Catheter between September 1, 2015 and June 1, 2017 in the present Cath Lab. A 6-Fr sheath was implemented via the radial approach in all cases. Indications for the use of Guidezilla catheter were as follows: difficulty in delivering the microcatheter, balloon or stent to the target lesion, even if the initial attempts using the abovementioned techniques failed. The clinical (age, gender, medical history, current clinical presentation and coronary angiography indication), angiographic (target lesion, type of lesion and character of lesion, such as tortuous, angulation, calcification and chronic total obstruction [CTO]) and procedural data (type of guiding catheter; guidewire and stent; and preprocess for the lesion) of these patients were collected and analysed.

Each target lesion was classified as type A, B1, $\mathrm{B} 2$ or $\mathrm{C}$ according to the definitions established by the American Heart Association/American College of Cardiology (AHA/ACC) [9]. A tortuous lesion was defined as having at least $3 \geq 45^{\circ}$ bends in vessel direction along the main trunk during the diastolic period [9]. Angulation was recorded as the angle formed between proximal and distal vessel axis ( $\geq 45^{\circ}$ moderate; $\geq 90^{\circ}$ severe) [8]. Calcification was identified based on density as visualized in the wall of the vessel before injecting a contrast agent [10].

Efficacy was defined as successful deployment of an interventional device at the target lesion and successful completion of PCI therapy. To evaluate safety, all procedure-related complications and major clinical events (including all-cause death, recurrence of myocardial infarction, intractable angina and repeated revascularization) were recorded during the in-hospital stay and follow-up period of at least 30 days.

The study protocol was approved by the Ethics Committee for Human Study, Second Xiangya Hospital, Central South University. The study was performed in accordance with the Declaration of Helsinki.

\section{Statistical analysis}

Statistical analyses were performed using SPSS for Windows version 22.0 (SPSS Inc., Chicago, IL, USA). Continuous variables were expressed as the mean \pm standard deviation, and categorical data were recorded as a percentage.

\section{Results}

Among the 1,542 patients who underwent PCI between September 1, 2015 and June 1, 2017 at our center, the Guidezilla extension catheter was used in 26 procedures among 25 patients (19 males and 6 females; age range $48-84$ years old, mean $67.6 \pm 8.92$ years old). Baseline characteristics are summarized in Table 1 . The most common indication for the procedure was acute coronary syndrome (unstable angina, ST-elevation myocardial infarction [STEMI] or non-ST-elevation myocardial infarction [NSTEMI]) (84\%). There were 3 patients with moderate/severe renal damage (chronic kidney disease grade $\geq 3$ ) before interventional treatment, but none of them suffered from radiographic contrast nephropathy after the operation, in which the iso-osmolar contrast agent Iodixanol (GE Healthcare, Norway) was used. All but 3 patients underwent PCI for the first time, and no patients required prophylactic intra-aortic balloon pump implantation.

In this study, a predominant target vessel was not observed (left anterior descending artery 
Table 1. Clinical data of patients who underwent $\mathrm{PCl}$ using Guidezilla Guide.

\begin{tabular}{|c|c|}
\hline Patients & 25 \\
\hline Age [years] & $67.6 \pm 8.92$ \\
\hline \multicolumn{2}{|l|}{ Gender: } \\
\hline Male & $19(76 \%)$ \\
\hline Female & $6(24 \%)$ \\
\hline Diabetes & $4(16 \%)$ \\
\hline Hypertension & $21(84 \%)$ \\
\hline Smoking & $16(64 \%)$ \\
\hline Body mass index $\left[\mathrm{m} / \mathrm{kg}^{2}\right]$ & $23.1 \pm 2.89$ \\
\hline Moderate/severe renal damage & $3(12 \%)$ \\
\hline Previous $\mathrm{PCl}$ & $3(12 \%)$ \\
\hline Prophylactic IABP & $0(0 \%)$ \\
\hline \multicolumn{2}{|l|}{ Angiography indication: } \\
\hline Stable CAD & $4(16 \%)$ \\
\hline Unstable angina & $11(44 \%)$ \\
\hline STEMI & $7(28 \%)$ \\
\hline NSTEMI & $3(12 \%)$ \\
\hline Procedure & 26 \\
\hline Target vessel: & $9(35 \%)$ \\
\hline LAD & $6(21 \%)$ \\
\hline LCX & $7(36 \%)$ \\
\hline \multicolumn{2}{|l|}{$\mathrm{RCA}$} \\
\hline \multicolumn{2}{|l|}{ Type of lesion: } \\
\hline B2 & $18(69 \%)$ \\
\hline C & $8(31 \%)$ \\
\hline
\end{tabular}

CAD - coronary artery disease; IABP - intra-aortic balloon pump; LAD - left anterior descending artery; LCX - left circumflex coronary artery; NESTEMI - non ST-elevation myocardial infarction; $\mathrm{PCl}$ - percutaneous coronary intervention; RCA - right coronary artery; STEMI - ST-elevation myocardial infarction

[LAD] vs. left circumflex coronary artery [LCX] vs. right coronary artery $[\mathrm{RCA}], 35 \%$ vs. $21 \%$ vs. $36 \%$, respectively). All of the lesions were type
$\mathrm{B} / \mathrm{C}$ as classified by the AHA/ACC (type B, 69\%; type $\mathrm{C}, 31 \%$ ), and most lesions exhibited severe calcification, proximal tortuosity and angulation. There was 1 case of CTO in the RCA and 2 cases of thrombus during primary PCI. The Guidezilla extension catheter was used to deliver a drugeluting stent through the complex lesion in these cases (Fig. 1).

Stent implantation was successfully performed in 23 out of 26 procedures ( $88.5 \%$ ), and PCI therapy failure occurred in only $3(11.5 \%)$ cases. Among these cases, one involved a lesion in the middle of the LCX with left main (LM) stenosis; LM artery was intubated at a shallow depth $(5.35 \mathrm{~mm}$ past the guiding catheter) to avoid aggravating the intimal injury. Operator uncertainty may have also contributed to the failed operation. In another case, a type $\mathrm{B}$ dissection occurred after the guidewire crossed the lesion and was pre-dilated; the stent could not be deployed at the appropriate position despite using the Guidezilla catheter, which may have been inserted into a false lumen. The last procedure failed because the stent was stripped from its delivery balloon as it had become deformed when crossing the collar segment of the Guidezilla catheter. Since the patient could not tolerate a prolonged operation, the procedure was terminated. In addition, the following techniques were used in several cases to further advance the Guidezilla catheter: the rotational atherectomy technique $(2 / 26,7.7 \%)$ and the multiple pre-dilatation technique $(2 / 26,7.7 \%)$ to modify the lesion; and the buddy wire technique $(4 / 26,15.4 \%)$ and the balloon anchoring technique $(9 / 26,34.6 \%)$ to generate a powerful pushing force.

Regarding safety, only 1 stent was stripped off of its delivery balloon $(3.8 \%, 1 / 26)$ without the occurrence of coronary dissection, air embolism,

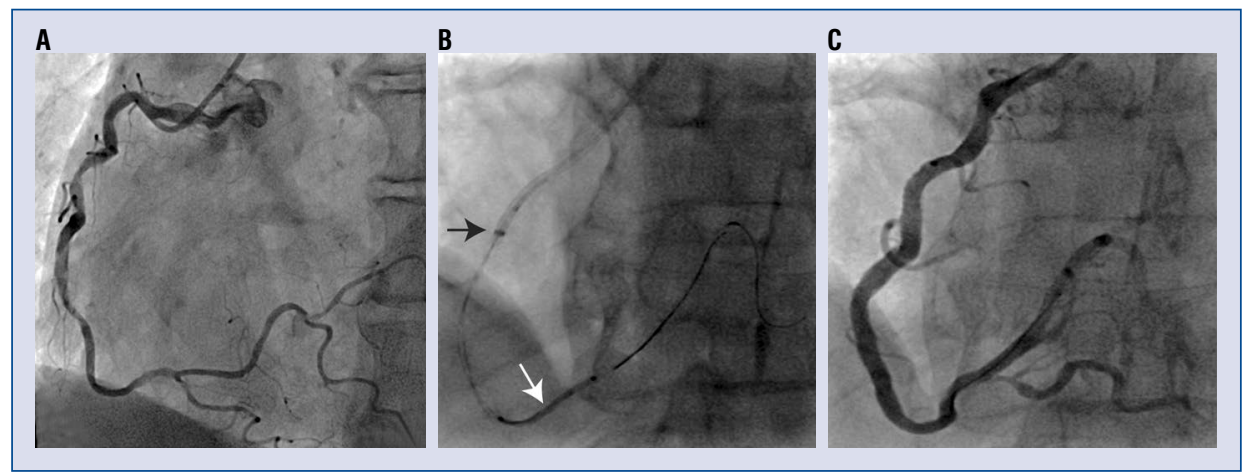

Figure 1. Successful stent implementation using the Guidezilla catheter. Angiography shows that the lesion located in the mid-right coronary artery has severe tortuosity and angulation (A). The Guidezilla catheter was inserted into the coronary artery at a depth of $50.53 \mathrm{~mm}$ (black arrow) to facilitate stent (white arrow) delivery (B). C. Angiography after stenting. 
Table 2. Summary of procedural characteristics.

\begin{tabular}{|c|c|c|c|c|c|c|c|c|c|}
\hline & $\begin{array}{l}\text { Lesion } \\
\text { position }\end{array}$ & $\begin{array}{l}\text { Type of } \\
\text { lesion }\end{array}$ & Challenge & $\begin{array}{l}\text { Guiding } \\
\text { catheter }\end{array}$ & Guide wire & Stent & $\begin{array}{l}\text { Depth of } \\
\text { intubation }\end{array}$ & $\begin{array}{l}\text { Special } \\
\text { operation }\end{array}$ & Result \\
\hline 1 & P-LCX & C & $\begin{array}{c}\text { Calcification } \\
\text { CTO }\end{array}$ & EBU 3.5 & Runthrough & $\begin{array}{c}\text { EXCEL } \\
2.5 \times 38\end{array}$ & 20.67 & I & Success \\
\hline 2 & M-LAD & B2 & Calcification & JL 3.5 & Rinato & $\begin{array}{c}\text { EXCEL } \\
2.75 \times 33\end{array}$ & 12.24 & $\begin{array}{c}\text { Muptile } \\
\text { pre-dilatation }\end{array}$ & Success \\
\hline 3 & M-LAD & C & Calcification & JL 4.0 & $\begin{array}{l}\text { Runthrough } \\
\text { Rinato }\end{array}$ & $\begin{array}{c}\text { EXCEL } \\
2.5 \times 28\end{array}$ & 32.39 & 1 & $\begin{array}{l}\text { Stent } \\
\text { loss }\end{array}$ \\
\hline 4 & M-LAD & B2 & $\begin{array}{l}\text { Calcification } \\
\text { angulation }\end{array}$ & JL 3.5 & $\begin{array}{c}\text { PILOT } 50 \\
\text { ASAHI SION }\end{array}$ & $\begin{array}{l}\text { LEPU } \\
2.5 \times 29\end{array}$ & 23.49 & $\begin{array}{c}\text { Buddy } \\
\text { wire/Balloon } \\
\text { anchoring }\end{array}$ & Success \\
\hline 5 & P-LCX & B2 & Calcification & EBU 3.5 & Runthrough & $\begin{array}{l}\text { PROMUS } \\
2.5 \times 20\end{array}$ & 16.68 & $\begin{array}{c}\text { Rotational } \\
\text { atherectomy }\end{array}$ & Success \\
\hline 6 & M-LAD & B2 & $\begin{array}{l}\text { Angulation } \\
\text { thrombus }\end{array}$ & JL 3.5 & Runthrough & $\begin{array}{l}\text { PROMUS } \\
2.5 \times 32\end{array}$ & 25.25 & $\begin{array}{c}\text { Balloon } \\
\text { anchoring }\end{array}$ & Success \\
\hline 7 & P-LCX & B2 & $\begin{array}{l}\text { Tortuosity } \\
\text { angulation }\end{array}$ & EBU 3.5 & Runthrough & $\begin{array}{l}\text { PROMUS } \\
2.75 \times 24\end{array}$ & 33.56 & $\begin{array}{l}\text { Balloon } \\
\text { anchoring }\end{array}$ & Success \\
\hline 8 & M-LAD & B2 & Calcification & EBU 3.5 & Runthrough & $\begin{array}{l}\text { PROMUS } \\
2.5 \times 32\end{array}$ & 28.19 & $\begin{array}{l}\text { Balloon } \\
\text { anchoring }\end{array}$ & Success \\
\hline 9 & M-RCA & B2 & $\begin{array}{l}\text { Tortuosity } \\
\text { angulation }\end{array}$ & EBU 3.5 & ASAHI SION & $\begin{array}{l}\text { PROMUS } \\
3.5 \times 28\end{array}$ & 16.67 & I & Success \\
\hline 10 & M-LCX & C & $\begin{array}{l}\text { Tortuosity } \\
\text { angulation }\end{array}$ & JL 3.5 & $\begin{array}{l}\text { ASAHI SION } \\
\text { Rintao }\end{array}$ & $\begin{array}{c}\text { EXCEL } \\
2.5 \times 28\end{array}$ & 6.84 & Buddy wire & Success \\
\hline 11 & M-RCA & B2 & $\begin{array}{l}\text { Tortuosity } \\
\text { angulation }\end{array}$ & JR 4.0 & ASAHI SION & $\begin{array}{c}\text { PROMUS } \\
4.0 \times 32\end{array}$ & 21.02 & l & Success \\
\hline 12 & M-RCA & B2 & $\begin{array}{l}\text { Angulation } \\
\text { thrombus }\end{array}$ & JR 4.0 & Rinato & $\begin{array}{l}\text { PROMUS } \\
3.5 \times 24\end{array}$ & 16.41 & $\begin{array}{l}\text { Balloon an- } \\
\text { choring }\end{array}$ & Success \\
\hline 13 & P-LAD & C & Calcification & JL 4.0 & ASAHI SION & $\begin{array}{l}\text { PROMUS } \\
2.5 \times 28\end{array}$ & 20.01 & $\begin{array}{c}\text { Rotational } \\
\text { atherectomy }\end{array}$ & Success \\
\hline 14 & M-RCA & B2 & Tortuosity & XBRCA & WHISPER & $\begin{array}{l}\text { EXCEL } \\
2.5 \times 28\end{array}$ & 32.36 & 1 & Success \\
\hline 15 & D-RCA & C & $\begin{array}{l}\text { Calcification } \\
\text { Tortuosity } \\
\text { angulation }\end{array}$ & XBRCA & $\begin{array}{l}\text { WHISPER } \\
\text { Field FC }\end{array}$ & $\begin{array}{l}\text { PROMUS } \\
2.5 \times 20\end{array}$ & 50.53 & Buddy wire & Success \\
\hline 16 & M-OM1 & B2 & $\begin{array}{l}\text { Tortuosity } \\
\text { dissection }\end{array}$ & JL 3.5 & STABILIZER & $\begin{array}{l}\text { Buma } \\
2.5 \times 20\end{array}$ & 57.00 & $\begin{array}{l}\text { Balloon } \\
\text { anchoring }\end{array}$ & Failure \\
\hline 17 & O-LCX & B2 & Calcification & JL 3.5 & Rinato & $\begin{array}{c}\text { EXCEL } \\
2.5 \times 28\end{array}$ & 5.35 & $\begin{array}{l}\text { Balloon } \\
\text { anchoring }\end{array}$ & Failure \\
\hline 18 & M-LCX & C & $\begin{array}{l}\text { Calcification } \\
\text { Tortuosity } \\
\text { angulation }\end{array}$ & JL 3.5 & ASAHI SION & $\begin{array}{c}\text { LEPU } \\
2.5 \times 29\end{array}$ & 53.34 & $\begin{array}{l}\text { Balloon } \\
\text { anchoring }\end{array}$ & Success \\
\hline 19 & M-LAD & B2 & Calcification & JL 4.0 & ASAHI SION & $\begin{array}{l}\text { PROMUS } \\
2.25 \times 32\end{array}$ & 36.42 & $\begin{array}{l}\text { Noncompliant } \\
\text { balloons } \\
\text { dilatation }\end{array}$ & Success \\
\hline 20 & M-LAD & B2 & Calcification & JL 3.5 & Rinato & $\begin{array}{c}\text { PROMUS } \\
2.75 \times 24\end{array}$ & 27.92 & I & success \\
\hline 21 & M-RCA & B2 & СТО & XBRCA & ASAHI SION & $\begin{array}{l}\text { PROMUS } \\
2.75 \times 36\end{array}$ & 43.72 & l & Success \\
\hline 22 & M-LCX & B2 & Tortuosity & EBU 3.0 & Runthrough & $\begin{array}{l}\text { EXCEL } \\
2.5 \times 1.4\end{array}$ & 28.92 & l & Success \\
\hline 23 & M-LAD & C & Tortuosity & JL 4.5 & $\begin{array}{l}\text { PILOT } 150 \\
\text { Rinato }\end{array}$ & $\begin{array}{c}\text { EXCEL } \\
3.0 \times 33\end{array}$ & 26.82 & Buddy wire & Success \\
\hline 24 & M-RCA & B2 & Tortuosity & AL 0.75 & ASAHI SION & $\begin{array}{c}\text { EXCEL } \\
2.5 \times 36\end{array}$ & 19.76 & l & Success \\
\hline 25 & M-LCX & B2 & $\begin{array}{l}\text { Tortuosity } \\
\text { angulation }\end{array}$ & JL 3.5 & Runthrough & $\begin{array}{c}\text { EXCEL } \\
2.75 \times 24\end{array}$ & 27.32 & / & Success \\
\hline 26 & M-RCA & B2 & Calcification & JR 4.0 & ASAHI SION & $\begin{array}{l}\text { PROMUS } \\
3.0 \times 24\end{array}$ & 29.43 & $\begin{array}{l}\text { Balloon } \\
\text { anchoring }\end{array}$ & Success \\
\hline
\end{tabular}

CTO - chronic total obstruction; D - distal; EBU — extra back up; JL — Judkins left; JR — Judkins right; LAD — left anterior descending; LCX — left circumflex coronary artery; $\mathrm{M}$ - middle; $\mathrm{O}$ - ostial; OM1 — first obtuse marginal; $\mathrm{P}$ — proximal; RCA — right coronary artery

myocardial ischemia or other serious complication. There were no cases of sustained pressure damping that required abandoning Guidezilla catheter usage in our study. No other major clinical event occurred during the hospitalization or follow-up period (the mean follow-up was approximately 40 days). The angiographic and procedural data are summarized in Tables 1 and 2. 


\section{Discussion}

Transradial catheterization has been widely used in recent years due to increased patient comfort and the reduced risk of hemorrhagic complications. However, its intrinsic weaknesses include inadequate back-up support and poor coaxiality due to different anatomical characteristics of the support point angulation [11]. However, our study highlighted the ability to apply the Guidezilla catheter using the radial approach, achieving a high success rate $(23 / 26,88.5 \%)$ while dealing with intricate coronary artery conditions. This study confirms that the transradial approach with the Guidezilla catheter may be a useful method and first-line alternative in many complex situations; furthermore, similar research using the Guidezilla catheter has not yet been performed.

Compared with the buddy wire, simple balloon anchoring and traditional 5-in-6 catheter techniques, the Guidezilla catheter was more flexible and useful when implemented with the 6-Fr catheter via a radial approach. The Guidezilla catheter has a larger inner lumen than the corresponding GuideLiner $^{\mathrm{TM}}$ catheter (Vascular Solutions, Minneapolis, MN) (0.057" vs. 0.056"), which ensures the delivery of various equipment; moreover, it is compatible with more guiding catheter sizes and is especially compatible with the 6-Fr catheter, which has a smaller external diameter (0.066”). In the present study, when standard Judkins guiding catheters $(16 / 26,61.5 \%)$ or other guiding catheters with increased back-up support (38.5\%), such as the EBU and XBRCA, failed to provide adequate back-up support, the Guidezilla catheter was used to avoid exchanging a new guiding catheter or using another access approach. The high procedural success rate $(88.5 \%)$ in this study is similar to that reported in previous studies using another extension catheter, the GuideLiner ${ }^{\mathrm{TM}}$ (ranges from $80 \%$ to $100 \%$, registries/case series including at least 10 patients from 2010 to 2016) [12]. Among failed cases, one involved an LCX ostial lesion with LM stenosis; hence, deep intubation was not appropriate, leading to the generation of insufficient support force for the delivery of a device across severely calcified lesions. It is known that increased intubation depth leads to stronger back-up force; however, the support design should be modified to overcome this difficulty.

In the present research, calcification, tortuosity, angulation and the presence of greater than two challenges were the main indications for the application of the Guidezilla catheter, and the primary purpose of deep intubation was to acquire more support force. The mean depth of intubation in this study was $27.90 \pm 12.23 \mathrm{~mm}$; the minimum depth of intubation was $5.35 \mathrm{~mm}$ in the ostial lesion of the LCX, and the maximum was $57.00 \mathrm{~mm}$ for a distal lesion of the obtuse marginal. Dursun et al. [6] reported that the mean intubation depth of the Guideliner catheter was $30.3 \pm 21.6 \mathrm{~mm}$ (min. $8 \mathrm{~mm}$; $\max .110 \mathrm{~mm}$ ). The stiff-yet-flexible stainless steel hypotube shaft of the Guidezilla catheter provides exceptional pushability and kink resistance when advancing the extension catheter. Nevertheless, it was sometimes difficult to advance the Guidezilla catheter to the appropriate location for sufficient back-up support; in these cases, several techniques could be used: a) Buddy wire technique, which uses another wire to stabilize the guiding catheter and increase support, including a third wire that acts as a sliding track to enhance pushing power; b) Anchoring balloon technique, in which a balloon is deployed distal to the target vessel in a small branch or in a stent that was previously placed at another vessel and dilated at low pressure while simultaneously and carefully pushing the Guidezilla catheter; and c) Elaborately modifying the lesion, multiple pre-dilatations (even with non-compliant balloons) and rotational atherectomy could be effective. All of these methods were used in our study to achieve positive results (Fig. 2). In certain lesions, such as proximal vessels with distorted and calcified segments or proximal vessels, the deeply inserted Guidezilla catheter is able to cross the lesion or stent, thus providing a strong support force and unhindered track for other equipment (Fig. 3).

Another application of the Guidezilla catheter is to facilitate the intervention of CTO lesions. Kovacic et al. [13] reported the use of a Guideliner catheter in a CTO procedure to assist balloon or micro-catheter advancement to the culprit lesion or to support the initial wiring of the lesion; the success rate was up to $85.7 \%$ (24/28). In this study, the Guidezilla catheter was used in 1 case to successfully deliver a stent across a CTO lesion in the RCA during an antegrade operation via the radial approach. Furthermore, Mozid et al. [14] described a novel and elegant modification of reverse controlled antegrade and retrograde subintimal tracking (reverse CART), "Guideliner reverse CART", which was able to shorten the distance between the sites of retrograde guidewire re-entry and antegrade guiding catheter re-entry. However, retrograde CTO procedures are generally performed from a transfemoral approach. Nevertheless, we believe that the Guidezilla catheter can also be 


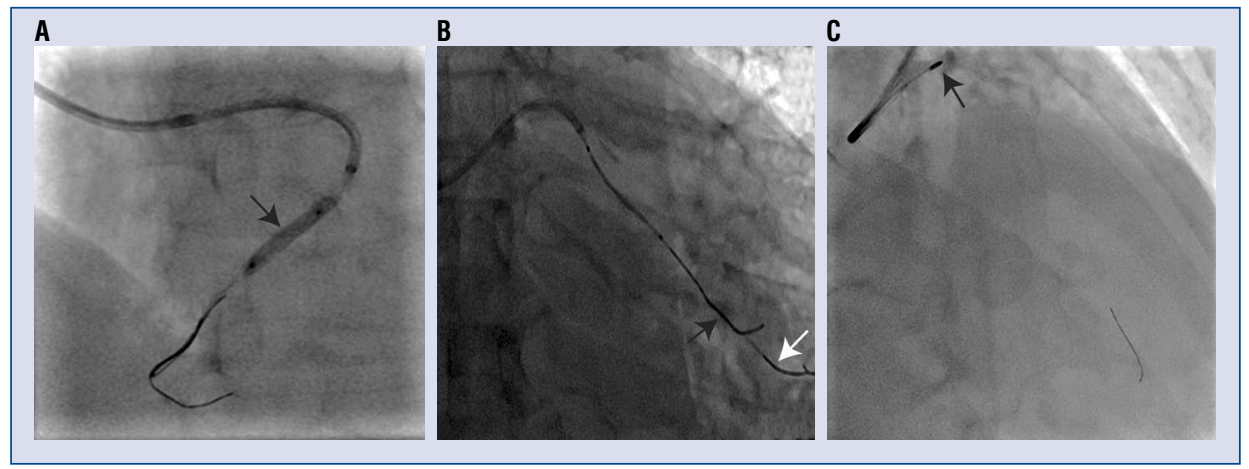

Figure 2. Patient No. 4: Anchoring balloon technique with an inflating balloon (black arrow) and advancement of the Guidezilla catheter to the target lesion (A). Patient No. 10: Buddy wire technique in which two guidewires (SION guidewire, white arrow, RINATO guidewire, black wire) were used for support (B). Patient No. 13: Rotational atherectomy technique in which a rotational atherectomy burr (black arrow, Rotalink $1.25 \mathrm{~mm}, 0.18 \mathrm{million}$ r/min) was used to prepare the lesion (C).

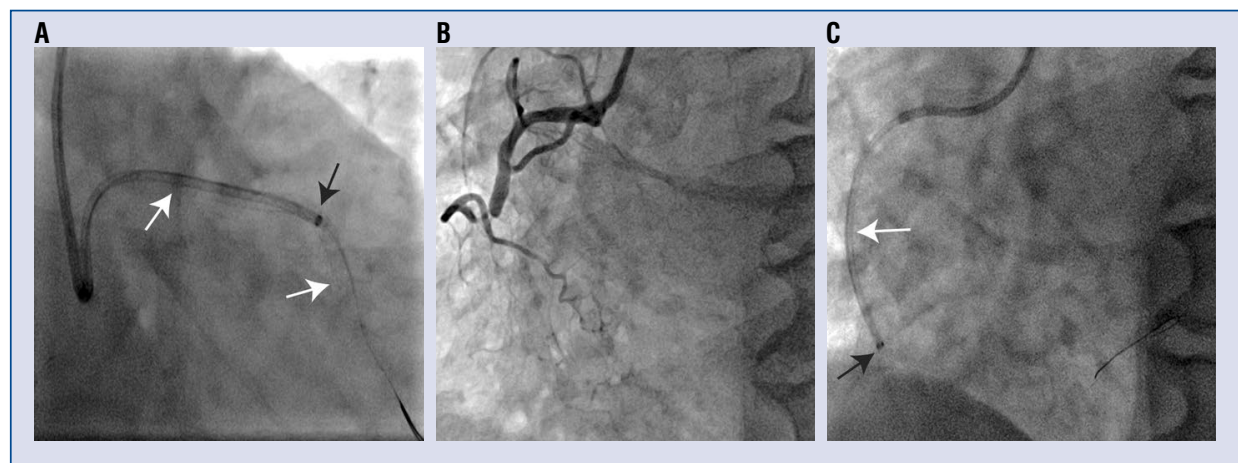

Figure 3. Patient No. 16: Inserting the Guidezilla catheter (black arrow) into a previously deployed stent (between the white arrows) (A). Patient No. 21: A chronic total occlusion lesion in the mid-right coronary artery (B) in which a Guidezilla catheter (black arrow) was pushed across the target lesion (white arrow) for increased support (C).

a useful tool for this situation and should be used in future surgeries in the present facility.

The Guidezilla catheter could also be used during emergency PCI with STEMI; the transradial approach for PCI in STEMI patients has been confirmed to be safe and effective compared with a transfemoral access according to a meta-analysis [15]. However, several challenges could occur during primary PCI with co-existing calcification, tortuosity, angulation or abnormal origin of the coronary artery, each of which would result in difficulty in the advancement of the equipment. Therefore, the Guidezilla catheter may help improve the ability to advance the balloon or stent and may be used for thrombus aspiration if a dedicated manual aspiration thrombectomy catheter failed to be deployed in the culprit lesion [16]. There were two primary $\mathrm{PCI}$ procedures recorded in this study, and a stent was successfully implemented in both cases. Other anecdotal benefits should also be noted; for instance, improving coaxial orientation and support in cases of anomalous origin of the coronary artery or graft vessels $[17,18]$; the selective injection of target coronary segments to reduce contrast use [19]; and the enhanced delivery of a bioresorbable vascular scaffold [20]. Additional applications may be developed in the near future. However, despite its usefulness in many situations, the greater cost of this catheter limits its large-scale application. Based on our experience, the patients in whom the Guidezilla catheter was used for PCI therapy spent approximately $23 \%$ more than average. This issue deserves additional attention, especially in developing countries

Only one complication $(3.8 \%, 1 / 26)$ occurred in this study; a stent was stripped off of its balloon while attempting to deliver it across the steel collar of the extension catheter. The stent was retrieved using a dual-guidewire winding technique in which a balloon was inflated distal to the guidewire and 


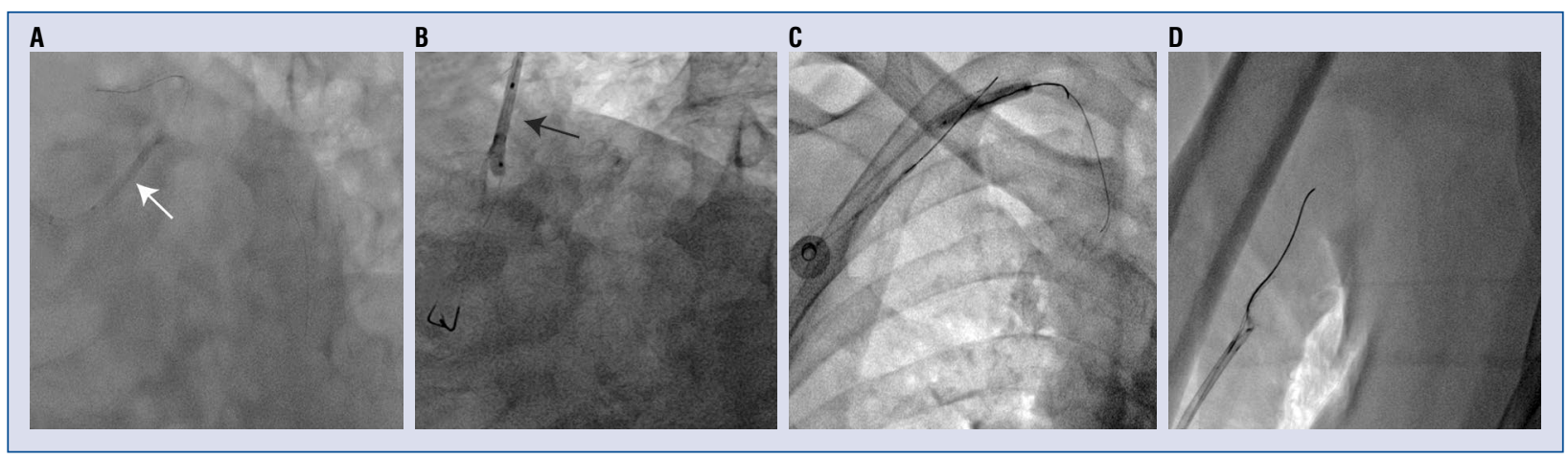

Figure 4. One case of a stripping-off complication; A. A stent (white arrow) transferred through the Guidezilla catheter; B. Stent (black arrow) stripped from the balloon; C. Using a dual-guidewire winding technique to retrieve the deformed stent; $\mathbf{D}$. The stent was pulled back into the guiding catheter.

fixed; subsequently, another guidewire was wound into a knot and used to cross the mesh such that the inside and outside of the bracket were contained by the distal end of the guide wire, which was retracted into the intracoronary guide catheter (Fig. 4). The stainless-steel collar embedded in the polymer of the Guidezilla catheter was designed to optimize accessory device delivery and support; however, reduced flexibility compared to an all-polymer collar, such as the Guideliner catheter, creates a new problem. The stent could easily hook onto the edge of the steel collar, increasing the risk of stent stripping. Waggoner et al. [21] reported another recent case in which stent stripping was caused by the Guidezilla catheter. Large and long stents are less flexible and should be carefully monitored for the development of this complication; additionally, careful withdrawal of the Guidezilla catheter when pushing the stent forward and caution to avoid placing the proximal Guidezilla collar on the angulated site of the vessel could reduce the risk of this complication. In addition, it is worth noting that the rotation and wrapping of the guidewire around the catheter should be avoided when pushing the equipment. Previous studies have reported that coronary dissection is a relatively common complication when using an extension catheter due to deep intubation and/or forceful injection of dye when the catheter is ejected forward. Waterbury et al. [22] reported that the incidence of this complication was $3.3 \%$. Coronary dissection was not observed in this research study. The soft, flexible and atraumatic tip of the Guidezilla catheter was designed to minimize the risk of injury to the vessel; however, in our experience, carefulness and slow operating speed as well as fluoroscopy play a key role in preventing this adverse event. During the procedure, no severe pressure dampening or ischemic event was recorded although they were frequently observed in 1 case series $(57 \%, 12 / 21)$ [23] using the Guideliner catheter and a transfemoral approach. Nevertheless, it should be noted that the Guidezilla catheter is compatible with the $6 \mathrm{~F}$ guiding catheter; thus, creating a side aperture on the tip of the guiding catheter which would influence the transit of the Guidezilla catheter and was therefore unsuitable. Hence, blood pressure, heart rate and other hemodynamic parameters should be carefully observed during the whole procedure to prevent the coronary blood flow being affected by Guidezilla catheter.

In conclusion, the findings described above revealed the safety and effectiveness of the Guidezilla catheter in complex lesions via a radial access as well as fewer associated complications.

\section{Limitations of the study}

In this study, only 26 procedures in 25 patients were evaluated; and therefore, a larger number of cases should be evaluated in future. Furthermore, a lack of experience in using the Guidezilla catheter for other applications, for example, stenting in graft vessels, locating the abnormal origin of a coronary artery and thrombus aspiration, and comparably less experience with CTO lesions represents an area of application with brighter prospects.

In addition, this study was designed as a retrospective study for only the Guidezilla catheter, and thus, it did not perform a comparison with other extension catheters (Guideliner and Guidion) with which the present participants have less experience. 


\section{Conclusions}

Although limited by experience, the Guidezil$\mathrm{la}^{\mathrm{TM}}$ extension catheter showed acceptable efficacy and safety when used for complex coronary lesions. This catheter was able to increase back-up support by deep intubation for the delivery of balloons or stents via the radial approach, thereby improving the success rate for the intervention of several complex lesions, such as those with calcification, tortuosity, angulation and CTO.

\section{Conflict of interest: None declared}

\section{References}

1. Burzotta F, Trani C, Mazzari MA, et al. Use of a second buddy wire during percutaneous coronary interventions: a simple solution for some challenging situations. J Invasive Cardiol. 2005; 17(3): 171-174, indexed in Pubmed: 15867450.

2. Jolly SS, Yusuf S, Cairns J, et al. Radial versus femoral access for coronary angiography and intervention in patients with acute coronary syndromes (RIVAL): a randomised, parallel group, multicentre trial. Lancet. 2011; 377(9775): 1409-1420, doi: 10.1016/ S0140-6736(11)60404-2, indexed in Pubmed: 21470671.

3. Mahmood A, Banerjee S, Brilakis ES. Applications of the distal anchoring technique in coronary and peripheral interventions. J Invasive Cardiol. 2011; 23(7): 291-294, indexed in Pubmed: 21725125.

4. Von Sohsten R, Oz R, Marone G, et al. Deep Intubation of 6 French Guiding Catheters for Transradial Coronary Interventions. J Invasive Cardiol. 1998; 10(4): 198-202, indexed in Pubmed: 10973341.

5. Duong T, Christopoulos G, Luna M, et al. Frequency, Indications, and Outcomes of Guide Catheter Extension Use in Percutaneous Coronary Intervention. J Invasive Cardiol. 2015; 27(10): E211-E215, indexed in Pubmed: 26429852.

6. Dursun H, Taştan A, Tanriverdi Z, et al. GuideLiner catheter application in complex coronary lesions: experience of two centers. Anatol J Cardiol. 2016; 16(5): 333-339, doi: 10.5152/AnatolJCardiol.2015.6214, indexed in Pubmed: 26168458.

7. García-Blas S, Núñez J, Mainar L, et al. Usefulness and safety of a guide catheter extension system for the percutaneous treatment of complex coronary lesions by a transradial approach. Med Princ Pract. 2015; 24(2): 171-177, doi: 10.1159/000369620, indexed in Pubmed: 25531292.

8. Ryan TJ, Faxon DP, Gunnar RM, et al. Guidelines for percutaneous transluminal coronary angioplasty. A report of the American College of Cardiology/American Heart Association Task Force on Assessment of Diagnostic and Therapeutic Cardiovascular Procedures (Subcommittee on Percutaneous Transluminal Coronary Angioplasty). Circulation. 1988; 78(2): 486-502, indexed in Pubmed: 2969312.

9. Turgut O, Yilmaz A, Yalta K, et al. Tortuosity of coronary arteries: an indicator for impaired left ventricular relaxation? Int J Cardiovasc Imaging. 2007; 23(6): 671-677, doi: 10.1007/s10554006-9186-4, indexed in Pubmed: 17216126.
10. Zaacks SM, Allen JE, Calvin JE, et al. Value of the American College of Cardiology/American Heart Association stenosis morphology classification for coronary interventions in the late 1990s. Am J Cardiol. 1998; 82(1): 43-49, indexed in Pubmed: 9671007.

11. Ikari Y, Masuda N, Matsukage T, et al. Backup force of guiding catheters for the right coronary artery in transfemoral and transradial interventions. J Invasive Cardiol. 2009; 21(11): 570-574, indexed in Pubmed: 19901410.

12. Fabris E, Kennedy MW, Di Mario C, et al. Guide extension, unmissable tool in the armamentarium of modern interventional cardiology. A comprehensive review. Int J Cardiol. 2016; 222: 141-147, doi: 10.1016/j.ijcard.2016.07.168, indexed in Pubmed: 27494727.

13. Kovacic JC, Sharma AB, Roy S, et al. GuideLiner mother-and-child guide catheter extension: a simple adjunctive tool in PCI for balloon uncrossable chronic total occlusions. J Interv Cardiol. 2013; 26(4): 343-350, doi: 10.1111/joic.12040, indexed in Pubmed: 23941652.

14. Mozid AM, Davies JR, Spratt JC. The utility of a guideliner ${ }^{\mathrm{TM}}$ catheter in retrograde percutaneous coronary intervention of a chronic total occlusion with reverse cart-the "capture" technique. Catheter Cardiovasc Interv. 2014; 83(6): 929-932, doi: 10.1002/ccd.25205, indexed in Pubmed: 24089343.

15. Singh S, Singh M, Grewal N, et al. Transradial vs transfemoral percutaneous coronary intervention in ST-segment elevation myocardial infarction: a systemic review and meta-analysis. Can J Cardiol. 2016; 32(6): 777-790, doi: 10.1016/j.cjca.2015.08.019, indexed in Pubmed: 27233893.

16. Farooq V, Serruys PW, Mustafa AHS, et al. Forward and back aspiration during ST-elevation myocardial infarction: a feasibility study. EuroIntervention. 2016; 11(14): e1639-e1648, doi: 10.4244/EIJV11I14A315, indexed in Pubmed: 27056124.

17. Farooq V, Mamas MA, Fath-Ordoubadi F, et al. The use of a guide catheter extension system as an aid during transradial percutaneous coronary intervention of coronary artery bypass grafts. Catheter Cardiovasc Interv. 2011; 78(6): 847-863, doi: 10.1002/ ccd.22942, indexed in Pubmed:21234926.

18. Ramanathan PK, Redfern R. Use of guideliner catheter for anomalous right coronary artery angiography and intervention. J Invasive Cardiol. 2013; 25(1): E20-E22, indexed in Pubmed: 23293184.

19. Pershad A, Sein V, Laufer N. GuideLiner catheter facilitated PCI: a novel device with multiple applications. J Invasive Cardiol. 2011; 23(11): E254-E259, indexed in Pubmed: 22045089.

20. Yew KL. Guidezilla guide extension catheter enhances the delivery of bioresorbable vascular scaffold in an anomalous coronary artery. Int J Cardiol. 2016; 223: 239-241, doi: 10.1016/j. ijcard.2016.07.299, indexed in Pubmed: 27541663.

21. Waggoner T, Desai H, Sanghvi K. A unique complication of the GuideZilla guide extension support catheter and the risk of stent stripping in interventional \& endovascular interventions. Indian Heart J. 2015; 67(4): 381-384, doi: 10.1016/j.ihj.2015.04.018, indexed in Pubmed: 26304575.

22. Waterbury TM, Sorajja P, Bell MR, et al. Experience and complications associated with use of guide extension catheters in percutaneous coronary intervention. Catheter Cardiovasc Interv. 2016; 88(7): 1057-1065, doi: 10.1002/ccd.26329, indexed in Pubmed: 26698371.

23. Luna M, Papayannis A, Holper EM, et al. Transfemoral use of the GuideLiner catheter in complex coronary and bypass graft interventions. Catheter Cardiovasc Interv. 2012; 80(3): 437-446, doi: 10.1002/ccd.23232, indexed in Pubmed: 21805572. 